\title{
The Cerebellar System and What it Signifies from a Biological Perspective: a Communication by Christfried Jakob (1866-1956) Before the Society of Neurology and Psychiatry of Buenos Aires, December 1938
}

\author{
D. E. Haines ${ }^{1}$ - M.-U. Manto ${ }^{2,3}$
}

Published online: 27 May 2016

(C) Springer Science+Business Media New York 2016

\section{Introduction}

Although the name Christfried Jakob may have largely receded from our collective memories, his significant and wideranging contributions to the field of neuroanatomy/ neuroscience is deeply embedded in the history of this topic. Some of his observations and approaches anticipated methodology that would not even occur to scientists or clinicians for, literally, decades to come. This is especially the case when it comes to the morphology, function, and clinical considerations of the cerebellum.

Jakob was the consummate observer of detailed morphology; his illustrations of both normal and pathological specimens were remarkably accurate, elegantly detailed, and intuitive. He viewed structure and function as integrated entities, somewhat like two sides of the same coin. Consequently, his view was that structure and function were inseparable and one could not be considered without the other. While commonplace in the current period, this insistence on structural

The article of Cerebellar Classic XII is available at http://dx.doi.org/10. 1007/s12311-016-0790-0 and the Commentary paper related to Cerebellar Classic XII is at http://dx.doi.org/10.1007/s12311-016-0791-z.

D. E. Haines

dhaines@wakehealth.edu

1 Department of Neurobiology and Anatomy, Wake Forest School of Medicine, 1 Medical Center Blvd., Winston-Salem, NC 27157-1010, USA

2 FNRS-Unité d'Etude du Mouvement, Université Libre de Bruxelles, ULB-Erasme, Route de Lennik 808, 1070 Brussels, Belgium

3 Service des Neurosciences, UMons, 7000 Mons, Belgium functional integration was less than commonplace around the beginning of the twentieth Century. In this respect, Jakob was well ahead of his time.

In 1901, imaging of the brain was not even an abstract concept, although experiments on potential techniques to visualize the cerebral vessels (angiography) were being conducted as early as the 1920s. It would take a number of years for these techniques to be perfected and subsequently used in the clinical setting.

Without even realizing it, Jakob, in some his illustrations of pathological and normal specimens [1], inadvertently anticipated an approach that would be absolutely essential to the diagnosis of the neurologically compromised patient, and to the interpretation of corresponding deficits as viewed in $\mathrm{CT}$ and MRI. Although these methods did not come into use until about 80 years after Jakob published his "Atlas of the Nervous System..." he presented a number of his cases in a format that represented, exactly, how the brain, and particularly the spinal cord, were viewed using these contemporary diagnostic procedures. In 47 figures on 15 Plates/Tables, Jakob represented the spinal cord in a clinical orientation (Fig. 1a); flipped top-to-bottom (anterior horn "up," posterior horn "down") when compared to the frequently used anatomical orientation (anterior horn "down," posterior horn "up"). When correlated with a CT at the same spinal level (Fig. 1b) this accomplished two important elements. First, it puts the locations of tracts and the somatotopy therein, in the exact orientation as they appear in the CT; the clinical view. Second, it established the laterality of the lesion (on the right or left) and, therefore, the side (right or left) of the deficit. For example, in the clinical orientation, the lesion in Fig. 1a is on the left side of the spinal 


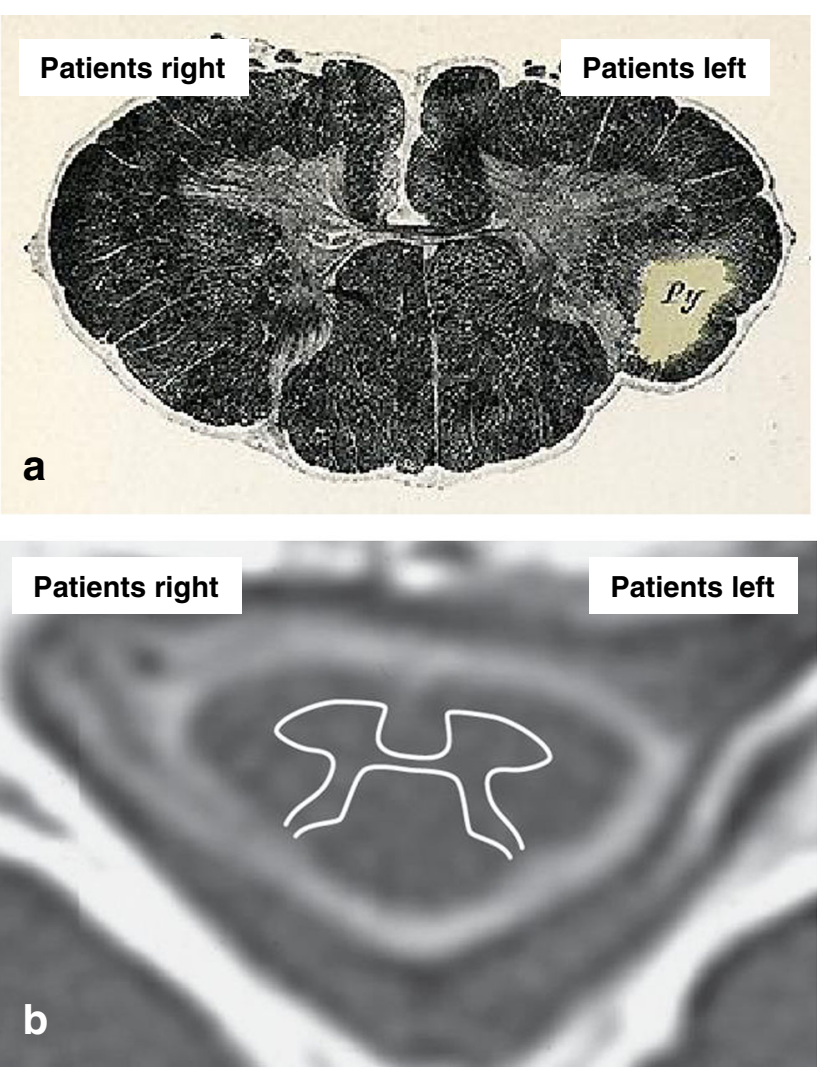

Fig. 1 a Figure 1 on Table 71 showing the cervical spinal cord with a damaged pyramidal tract (Py) on the patients left side in the clinical orientation. From C. Jakob, Atlas of The Nervous System Including an Epitome of The Anatomy, Pathology, and Treatment, W. B. Saunders \& Company, 1901. b CT of the corresponding cervical level overlaid with the position and orientation of the spinal cord gray matter. Note the orientation of the spinal cord gray matter and the fact that it is exactly the same as in the drawing of Jakob in a. From D. E. Haines, Neuroanatomy in Clinical Context, 9th Ed., Baltimore, Wolters Kluwer/ Lippincott Williams \& Wilkins, 2015 cord and, considering this is caudal to the motor (pyramidal) decussation, the motor deficits are also on the left side.

This clearly illustrates that some of the contributions of Jakob were remarkably relevant not only to his time, but to future generations decades after his death. In fact, his images could be used in any contemporary basic science or clinical neuroscience course. Obviously, Jakob did not have any concept regarding the central nervous system orientation in $\mathrm{CT}$ so he described the damaged pyramidal tract as on the "...right..." side (Fig. 1a). However, this image, published in 1901, would make perfect sense to, and be correctly interpreted by, anyone in a contemporary (2016) neuroradiology suite. This clearly shows that some of the contributions of Christfried Jakob had a timeless quality that, unbeknownst to him, would be perfectly applicable to basic science and clinical applications 115 years after their initial presentation His contributions in the field of cerebellar disorders included reports on olivo-pontocerebellar atrophy (OPCA) and cerebellar atrophy associated with intellectual deterioration. No doubt that Jakob can be considered as a pioneer and that his works deserve to be included in the Cerebellar Classics.

\section{References}

1. Jakob C. Atlas of the nervous system including an epitome of the anatomy, pathology, and treatment. In: Fisher ED, editor. Authorized translation from the second revised German Edition. Philadelphia: W. B. Saunders \& Company; 1901. 